\title{
TÉCNICAS DE CRIATIVIDADE COMO MEIO FACILITADOR DO PROCESSO CRIATIVO NAS ORGANIZAÇÕES
}

Creativity techniques as a facilitator in the creative process in organizations

Las técnicas de creatividad como um facilitador en el proceso creativo em las organizaciones

\author{
Cristiano Max Pereira \\ Pinheiro \\ Doutor em Comunicação Social e \\ Professor do Mestrado em \\ Indústria Criativa na Universidade \\ Feevale. \\ maxrs@feevale.br \\ Dusan Schreiber \\ Doutor em Administração e \\ Professor na Universidade Feevale \\ dusan@feevale.br \\ Bruna Haubert \\ Mestranda em Indústria Criativa \\ na Universidade Feevale \\ brunahaubert@feevale.br
}

\section{Resumo}

$\mathrm{Na}$ efervescência da valorização do indivíduo, o desenvolvimento econômico tem sido associado à contribuição da criatividade nas organizações. Algumas técnicas de processos criativos se evidenciam como facilitadoras no âmbito organizacional. Neste contexto, o artigo tem como objetivo apresentar técnicas de criatividade utilizadas no meio organizacional para desenvolvimento de ideias. Para atender a esse objetivo, adotou-se o método exploratório e descritivo e como procedimento técnico optou-se pela realização de uma pesquisa bibliográfica. Como resultado evidenciou-se a importância do ser humano como ator principal nos processos criativos, e percebeu-se que sem o envolvimento das pessoas, as técnicas não geram resultados per se.

Palavras-chave: Criatividade. Técnicas de Criatividade. Processos Criativos. Processos Criativos nas Organizações. 


\begin{abstract}
In this effervescence of the individual's valuation, economic development has been associated with creativity contribution in organizations. Some techniques are evident as facilitators of creative processes in the organizational context. In this context, the paper aims to present creativity techniques used in the organizational environment for developing ideas. To meet this goal, was adopted the exploratory and descriptive method and as a technical procedure was chosen for conducting a literature. As a result was showed the importance of the human being as the main actor in the creative process, and it was noticed that without the involvement of people, techniques do not generate results per se.
\end{abstract}

Key words: Creativity. Creativity Techniques. Creative Processes. Creative Processes in Organizations.

\title{
Resumen
}

En esta efervescencia de la valoración del individuo, el desarrollo económico se ha asociado con la contribución de la creatividad en las organizaciones. Algunas técnicas de procesos creativos son evidentes como facilitadores en el contexto de la organización. En este contexto, el presente trabajo tiene como objetivo presentar las técnicas de creatividad utilizadas en el entorno de la organización para el desarrollo de las ideas. Para cumplir con este objetivo, se adoptó el método exploratorio y descriptivo y como un procedimiento técnico fue elegido una búsqueda en la literatura. Como resultado se demostró la importancia del ser humano como actor principal en el proceso creativo, y se observó que sin la participación de la gente, las técnicas no generan resultados per se.

Palabras clave: Creatividad. Técnicas de creatividad. Procesos Creativos. Procesos Creativos en las Organizaciones.

\section{INTRODUÇÃO}

A criatividade tem se tornado a verdadeira riqueza das nações na economia do século XXI (UNESCO, 2013). Neste contexto, emergem novos modelos de infraestrutura econômica com o intuito de dar suporte à criatividade e estimular os indivíduos no desenvolvimento de novos produtos e processos (FLORIDA, 2011). O processo criativo se relaciona à solução de problemas e no que se refere às estratégias, evidencia-se que, em geral, são advindas de experiências pregressas. Sobretudo, os trabalhadores criativos são vistos como solucionadores de problemas e sob esta perspectiva, as organizações buscam redefinir a gestão de seus negócios como meio de se adequar às novas condições que o referido contexto institui.

Respaldando o exposto, Catmull e Wallace (2014), Gurteen (1998) evidenciam o entendimento de que todo indivíduo tem potencial para ser criativo e esta criatividade pode 
ser apresentada de diversas formas. Para os referidos autores, incentivar o desenvolvimento da criatividade é um ato nobre.

De acordo com Florida (2011), o trabalho criativo não pode ser padronizado como era previsto no trabalho maquinal das fábricas e escritórios da era industrial, século XVIII. É preciso compreender a necessidade de redefinir as práticas e saber como agir para que a mudança ocorra assertivamente, proporcionando benefícios não só de ordem econômica, mas também social e cultural. Os gestores das organizações devem reconhecer as variáveis que influenciam a criatividade no meio organizacional para promovê-las, a fim de obter melhores resultados nos processos criativos.

Em alguns aspectos, o comportamento organizacional evidencia-se como um jogo, estimulado pelas interações sociais e comunicacionais que incitam o pensamento criativo por meio do desenvolvimento de competências e habilidades (GREIMAS, 1998; MAINEMELIS; RONSON, 2006; GURTEEN, 1998). King e Schlicksupp (1999) apresentam algumas técnicas de criatividade, as quais afirmam serem as mais eficazes em processos de criatividade, no meio organizacional. No entanto, os referidos autores advertem que algumas ações devem ser tomadas antes de aplicar as técnicas efetivamente, para assegurar um resultado positivo. Da mesma forma, destaca-se a importância de considerar a singularidade dos integrantes de uma equipe, para ampliar a capacidade criativa (KING; SCHLICKSUPP, 1999).

Nesta perspectiva, este ensaio teórico desenvolve uma análise sobre técnicas de criatividade, aplicadas em ambientes organizacionais que visam desenvolver ideias para solucionar problemas através da intensificação dos processos comunicacionais relacionados a dinâmica de criação. Para alcançar os objetivos desta pesquisa adotou-se o método de mineração de dados, em bases SCOPUS e SCIELO, usando palavras-chave "creative tools", "tools for creativity", juntas e separadas, seguindo as recomendações de autores que versam sobre o referido método (ADRIAANS; ZANTINGE, 1996, ATEWELL; MONAGHAN, 2015). A pesquisa foi realizada em 26 de setembro de 2015.

A pesquisa pode ser considerada exploratória e descritiva, pois com base nos resultados da etapa anterior, de mineração de dados. Foram selecionados os textos que versam sobre as técnicas de criatividade, constituídos de trabalhos, entre livros e artigos científicos, e analisados por meio de leitura inicial de resumos, visando a sua classificação, e, na sequência, leitura integral, dos textos julgados mais aderentes ao foco da pesquisa.

Desta forma foi possível construir o texto final, apresentando conceitos acerca de criatividade, composto por algumas técnicas de criatividade, as quais são empregadas para o 
desenvolvimento de processos criativos, para definição e solução de problemas. Este procedimento pode ser caracterizado como uma pesquisa bibliográfica com abordagem qualitativa (PRODANOV; FREITAS, 2013).

\section{DESENVOLVIMENTO}

A criatividade tem atraído, cada vez mais, o interesse de gestores organizacionais. Um dos principais motivos é a necessidade de tomar decisões imediatas em um cenário marcado por rápidas mudanças e riscos (ALENCAR, 1996). Permitir que os colaboradores contribuam nos processos criativos em busca de novas soluções pode ser relevante tanto para solução de problemas, como também para o desenvolvimento de novos produtos e serviços (CATMULL; WALLACE, 2014). Ainda que a criatividade seja interpretada de forma positiva, se faz necessário destacar que apenas $2 \%$ dos novos modelos de gestão incluem na sua concepção a criatividade. Como resultado é possível perceber que as organizações exploram diminutamente o potencial criativo dos colaboradores que as compõem (MORAES; LIMA in ALENCAR; BRUNO-FARIA; FLEITH, 2010).

Quando se versa sobre criatividade, em termos de definição de um conceito, Predebon (2005), Kaufman e Baer (2012) afirmam que não há como conceituar corretamente o que é criatividade em uma única definição, pois o assunto é amplo e para cada pessoa pode haver uma definição diferente.

Newbigin (2010, p. 16) sinaliza que "a criatividade é um processo disruptivo que questiona os limites e os pressupostos estabelecidos". Corroborando o exposto, Gurteen (1998) e Lubart (2007) contribuem para o debate e afirmam que a criatividade apoia-se no pensamento divergente, ou seja, na geração de novas ideias a partir do conhecimento existente. O produto deste pensamento, quando aplicado, pode ser a inovação (AMABILE, 1998).

Csikszentmihalyi (2009) ressalta a importância de estudar a criatividade, pois os resultados da criatividade enriquecem a cultura e melhoram a qualidade de vida das pessoas. Neste sentido, o autor salienta que os problemas tendem a ser resolvidos quando se dedica atenção aos mesmos e analisam-se possibilidades de soluções criativas. Cabe destacar que a criatividade não pode ser considerada um fenômeno individual, mas sim como um resultado que surge da interação entre pensamentos e um contexto sociocultural (CSIKSZENTMIHALYI, 2009. KING; SCHLICKSUPP, 1999). 
Amabile (1998) conceitua a criatividade no ambiente organizacional como a geração de ideias que podem ser úteis à organização. A autora evidencia que a criatividade pode beneficiar todas as áreas de uma empresa e não somente processos de $\mathrm{P} \& \mathrm{D}$ e marketing. $\mathrm{O}$ pensamento criativo relaciona-se com a capacidade de um indivíduo solucionar problemas, por meio de um conjunto de novas combinações (AMABILE, 1998; GURTEEN, 1998).

No campo organizacional, os gestores têm despertado a consciência para o potencial criativo que seus colaboradores podem oferecer. Neste sentido, aos poucos, a criatividade está sendo estudada e explorada, positivamente, em busca de melhores resultados frente ao contexto em mudança. (PUCCIO; CABRA in KAUFMAN; STERNBERG, 2010). Não são as organizações que se readaptam às mudanças, mas sim os indivíduos que as integram e constituem novos arranjos organizacionais. Nesta abordagem a criatividade surge como um resultado da interação entre pessoas, processos e o ambiente em que elas atuam (PUCCIO; CABRA in KAUFMAN; STERNBERG, 2010, CSIKSZENTMIHALYI, 2009).

A criatividade por si só não garante resultados positivos, pois depende do ecossistema que a circunda. Alencar (1996) indica a necessidade de considerar os fatores internos, em especial as práticas, normas e cultura da organização, para alinhá-las com os estímulos e incentivos aos colaboradores para gerar ideias e compartilhá-las com a organização. Para o referido autor, os fatores externos também são relevantes e determinantes para incentivar as práticas criativas.

Amabile (1998) expõe o fato de que a criatividade é prejudicada nas organizações todos os dias pelas exigências de produtividade, pelo maior controle. No entanto, para Amabile (1998) é possível maximizar ambas as frentes, a criatividade e a produtividade. A criatividade representa o resultado da soma de três elementos: especialidade, motivação e habilidade de pensamento criativo (AMABILE, 1998). Por este motivo, sugere-se que no ambiente organizacional, o gestor se aproprie do conhecimento, tanto do modelo preconizado como dos processos internos, e práticas organizacionais consolidadas, para poder criar condições favoráveis ao desenvolvimento do pensamento, da ideia e da criatividade, a partir destes três elementos. 


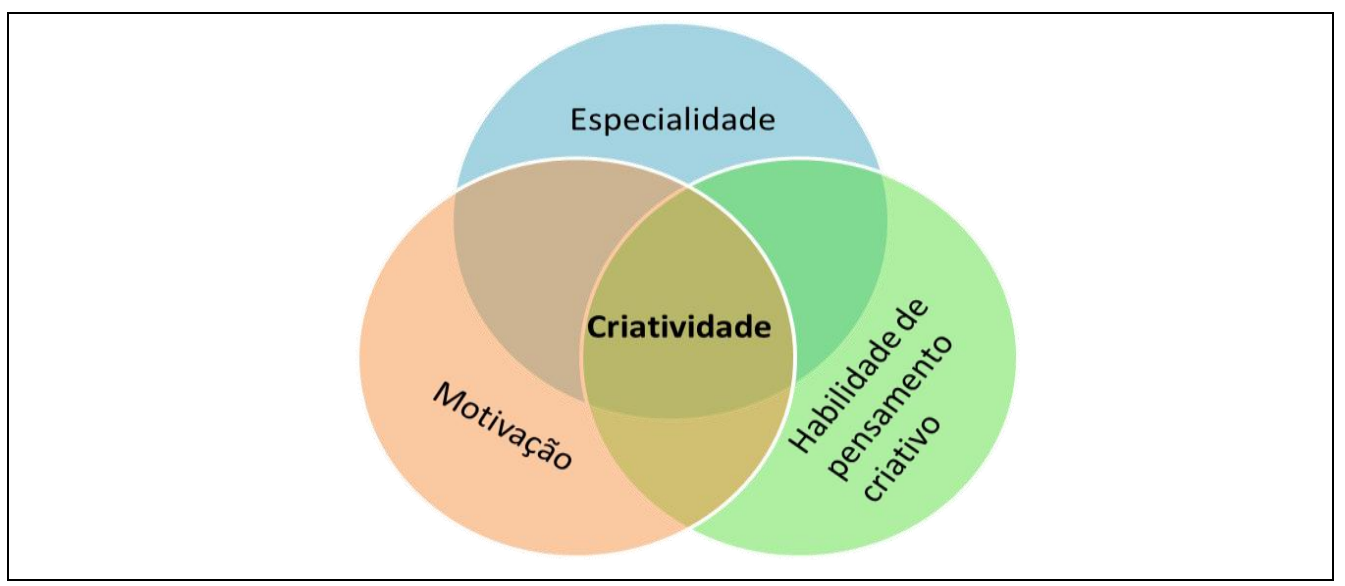

Figura 1 - Os três componentes da criatividade.

Fonte: Adaptado de Amabile (1998, p. 78, tradução nossa).

Conforme ilustra-se na Figura 1, a criatividade está posicionada como elemento central e diretamente correlacionado com a motivação, habilidade de pensamento criativo e a especialidade. A especialidade corresponde ao conhecimento técnico de cada indivíduo, no domínio de seu trabalho. O pensamento criativo é a aptidão de solucionar problemas gerando ideias a partir da recombinação de elementos existentes. O terceiro elemento que influencia a criatividade é a motivação, seja ela extrínseca (externa ao indivíduo) ou intrínseca (motivação pessoal, interna ao indivíduo) (AMABILE, 1998).

A soma destes fatores favorece o processo criativo, ou seja, se um gestor souber como acionar estes elementos em conjunto provavelmente ele obterá resultados positivos em relação à criatividade de seus colaboradores, levando em consideração a singularidade de cada indivíduo, que se encontra em níveis diferentes de cada um dos referidos elementos. Neste caso, o diálogo pode se constituir em uma técnica poderosa de criatividade, pois, por meio da interação social, os indivíduos podem trocar conhecimentos e rever seus próprios pressupostos, redefinindo de forma colaborativa os paradigmas (GURTEEN, 1998).

Neste sentido, as técnicas de criatividade surgem como ferramentas que contribuem na análise das oportunidades de um modo diferente do comum, para então fazer novas associações e conceber algo distinto. Clegg e Birch (2000) descrevem diversas técnicas de criatividade que facilitam a identificação do problema, o qual nem sempre está claro. Posteriormente, apresentam-se as técnicas que auxiliam na identificação de soluções para os problemas evidenciados.

King e Schlicksupp (1999) mencionam que pensar como sempre se pensou nem sempre produz os resultados esperados, pois tendem a reproduzir os resultados já alcançados. Nesta perspectiva entende-se que as empresas precisam de pensamentos criativos para ANIMUS Revista Interamericana de Comunicação Midiática 
solucionar problemas e criar novos produtos. Nesta perspectiva, os autores descrevem diversas técnicas de criatividade e afirmam que a seleção de um conjunto adequado de ferramentas, é decisiva para a concepção do processo criativo. É preciso admitir flexibilidade de pensamento, contestar pressupostos, transformando padrões e permitindo a reorganização de elementos de um problema.

Para fins desta pesquisa, buscou-se apresentar e restringir-se à exposição de diferentes perspectivas e autores que abordam conceitos de criatividade, não havendo a intenção de aprofundar o debate. $\mathrm{O}$ exposto constitui base para a apresentação de técnicas de criatividade, considerando as particularidades das referências identificadas.

King e Schlicksupp (1999), amparados por outros autores, elencam as técnicas de acordo com o tipo de problema e variáveis situacionais do requerente, como exemplo: tempo disponível, tamanho do grupo, nível de conhecimento do problema, entre outros aspectos. Neste sentido, a criatividade tem sido apontada como uma valiosa ferramenta na estratégia de desenvolvimento das organizações.

\subsection{Métodos de Criatividade}

Um processo de criatividade requer esforços, seja de um indivíduo ou de uma equipe, e pode resultar em novos projetos, produtos e ideias, passíveis de aplicação prática. $\mathrm{O}$ pensamento criativo normalmente é associado ao pensamento divergente, pois envolve ideias e experimentações inusitadas que cunham diversas possibilidades originais (KING; SCHLICKSUPP, 1999).

A capacidade criativa pode ser estimulada, através do ambiente, de técnicas e ferramentas. Um ambiente criado para acolher as ideias criativas sem críticas, oferece um clima de liberdade que incentiva o desenvolvimento de ideias e de concepção de novas perspectivas e formas de interpretar a realidade. O trabalho em equipe é uma medida que favorece o desempenho dos processos mentais, devido à troca de informações e conhecimentos heterogêneos e singulares a cada indivíduo (KING; SCHLICKSUPP, 1999).

No processo de geração de ideias, a soma das habilidades e experiências de cada colaborador tende a agregar e potencializar o desempenho coletivo. No entanto, para um aproveitamento melhor do desempenho criativo individual dos integrantes, é importante a mediação do processo de criatividade por meio de um método que conecte estes integrantes sinergicamente, aproveitando o potencial criativo do grupo, ao máximo. King e Schlicksupp 
(1999) sublinham que um trabalho em equipe, com bom rendimento, comumente se torna autossustentado em função da qualidade alcançada nos resultados.

Mainemelis e Ronson (2006) analisaram o comportamento organizacional como um jogo, em um estudo que promoveu a relação entre o jogo e a criatividade. Para os autores, o ato de jogar estimula o desenvolvimento da criatividade no campo organizacional, embora muitas organizações ainda considerem o jogo apenas como uma questão de distração. O jogo pode fomentar a capacidade de recombinar elementos existentes e promover a integração entre os participantes, que é uma situação desejável para propiciar o ato de criatividade, conforme abordado por King e Schlicksupp (1999).

Um jogo como engajamento, estimula a criatividade por meio das dimensões cognitivas e afetivas que o envolvem. Estudos realizados no campo de psicologia cognitiva têm evidenciado que o jogo envolve uma grande quantidade de transformações mentais e pensamento divergente, pois estimula o imaginário e o simbólico (MAINEMELIS; RONSON, 2006).

O jogo, no ambiente de trabalho, permite que os indivíduos desenvolvam suas habilidades, explorando suas competências através de desafios. Sob outro ponto de vista, a integração que ocorre por meio de um jogo no ambiente de trabalho, além de promover a criatividade, pode representar uma estratégia para que os colaboradores contribuam espontaneamente com ideias, que em outra situação não se sentiriam seguros para expor.

Gurteen (1998) também faz a associação entre criatividade e um jogo, relatando que um processo de criatividade joga com palavras, conceitos e também metáforas, sem fronteiras ou limitações. A essência deste jogo, para Gurteen (1998), é que nada é estático ou inalterável. Cada interação de nossas vidas pode ser visto como um jogo, e no mundo empresarial não é diferente. O jogo inicia-se com as interações sociais, com base no entendimento de que a troca de experiências e conhecimentos são oportunidades de aprendizagens que estimulam nossas capacidades cognitivas. Este processo incentiva a criatividade, ao relacionar elementos conhecidos com elementos novos.

Corroborando o exposto, King e Schlicksupp (1999) afirmam que o uso de processos ou técnicas para solução de problemas em uma organização é altamente eficaz para estimular o pensamento e aprendizagem criativa. As organizações podem optar entre diversos modelos existentes, sendo que muitas vezes os processos que representam a estrutura organizacional, vêm com fases pré-determinadas, como em um jogo. Visando contribuir para a concepção do 
processo de criatividade, os referidos autores sugerem a aplicação de técnicas que deem suporte à fase de definição do problema e posteriormente à geração de ideias.

Neste sentido, as técnicas de criatividade podem contribuir, de forma relevante, para a solução criativa de problemas, pois facultam a efervescência de ideias através de insights e a flexibilidade do pensamento, por desafiarem pressupostos convencionais, apoiarem a interdisciplinaridade e também por permitirem reorganizar os elementos de um problema (KING; SCHLICKSUPP, 1999). As técnicas de criatividade podem favorecer o processo de inovação, contribuindo no processo criativo para definição do problema e também para selecionar e desenvolver ideias na prática (KING; SCHLICKSUPP, 1999; CLEGG; BIRCH, 2000). Considerando o exposto, apresentam-se a seguir as técnicas de criatividade propostas sob os princípios evidenciados.

\subsubsection{Redefinição Heurística}

Partindo da premissa que identificar o problema ou desafio a ser solucionado é uma fase importante, a Redefinição Heurística é uma técnica que contribui neste processo com a proposição de desmembrar os elementos de um sistema para posteriormente arquitetar uma nova estrutura (REVELLE, 2004). À esta etapa do processo, de rearquitetar os elementos, Lubart (2007) conceitua como combinação seletiva, ao qual ele atribui a capacidade de unir elementos de forma que gerem uma nova ideia. Esta técnica não requer uma grande equipe e normalmente é aplicada quando o problema não está claro e requer uma análise aprofundada (KING; SCHLICKSUPP, 1999).

De modo geral, a Redefinição Heurística é um método para compreender um problema como um sistema e sob esta perspectiva, detalhar os elementos deste sistema. King e Schlicksupp (1999), Silverstein, Samuel e De Carlo (2012) e ReVelle (2004) sugerem apresentar estas informações em um fluxograma ou diagrama de setas, por exemplo. Cada elemento é analisado em profundidade para compreender sua influência (positiva ou negativa) no sistema como um todo. Para assegurar o nível de detalhamento da descrição dos elementos, sugere-se a utilização de perguntas como: O que? Onde? Quando? Por quê? Quem (causa ou sofre a ação)? (KING; SCHLICKSUPP, 1999).

A partir das respostas obtidas às referidas questões, emergem declarações de problemas, entre as quais será eleita a que apresenta maior aderência com a meta estabelecida. Elabora-se uma matriz para que se possa classificar cada enunciado, atribuindo pontos de 1 a 
3, sob os critérios de possibilidade de alcançar a meta, facilidade de implementação e impacto esperado sobre a meta (KING; SCHLICKSUPP, 1999). Vale destacar que nem sempre a maior pontuação representa o maior nível de alinhamento com a estratégia da empresa, sendo a sua finalidade, oferecer elementos para a equipe discutir os resultados encontrados e decidir, na sequência, quais os aspectos que serão melhor explorados.

\subsubsection{Bússola}

Uma técnica relativamente simples e eficaz é a Bússola, utilizada como suporte à definição de problemas e sua utilidade principal constitui-se em oportunizar uma exposição ampla do problema, previamente escolhido (CLEGG; BIRCH, 2000). A técnica consiste em, inicialmente fazer uma afirmação sobre o problema a ser investigado com base em: "por quê?". As respostas obtidas são anotadas, e para cada uma delas é utilizada novamente a mesma questão, obtendo-se, desta forma, novas respostas, aplicando-se a mesma pergunta, até que se esgotem as alternativas de respostas à questão proposta.

Entende-se que, desta forma, será possível chegar a uma nova configuração do problema que tenha mais relevância do que a sua descrição inicial (CLEGG; BIRCH, 2000). Esta técnica permite pensar o problema sob diferentes perspectivas, a medida em que surgem novos elementos a cada ciclo de pergunta-respostas. Davidson e Sternberg (2003) complementam ao exposto, afirmando que o pensamento que diverge e questiona o que está dado como verdade, permite um processo crítico que contribui para a definição do problema de forma mais concisa, pois visa esgotar as dúvidas que possam surgir ao questionar os porquês. Estes elementos podem estar sendo inibidos pela afirmação inicial e são abarcados ao longo do tempo com esta linha de pensamento.

\subsubsection{Brainstorming}

O Brainstorming foi criado em 1939 por Alex Osborn e significa, em sua concepção, cérebro para criar ideias para resolver um problema (OSBORN, 1954). Esta técnica, que auxilia no processo de geração de ideias, surgiu a partir da análise das causas que impediam a eficácia de uma reunião, e facultou determinar um conjunto de comportamentos que visam reduzir as distrações e potencializar o resultado criativo para soluções de problemas (KING; SCHLICKSUPP, 1999). 
O objetivo principal do Brainstorming é encontrar soluções para problemas, a partir do conhecimento que o grupo possui. Tem-se como principal premissa, a suposição de que todas as ideias possuem o mesmo valor. Mais do que uma técnica de criatividade, ela pode ser considerada como uma forma de criar um novo paradigma cultural, pois assegura que os indivíduos não trabalhem isolados e busquem soluções na sabedoria coletiva (KELLEY, LITTMAN, 2001).

A técnica é normalmente aplicada quando o problema requer um novo conceito ou soluções alternativas dentro de uma área de conhecimento. O Brainstorming pode ser aplicado mesmo quando o tempo disponível for limitado. Não requer um conhecimento prévio sobre a técnica, nem mesmo um conhecimento aprofundado sobre o problema. Por outro lado, em função destas características, requer um grupo maior de integrantes, para que seja possível gerar a maior variedade de ideias (KING; SCHLICKSUPP, 1999).

A técnica é descrita por King e Schlicksupp (1999) em 4 etapas principais: (1) identificar o grupo apropriado para gerir o Brainstorming, a partir do conhecimento e experiência de cada indivíduo. (2) apresentar as regras e estabelecer os tópicos e objetivos. (3) realizar o Brainstorming, gerando o máximo de ideias possíveis. (4) transcrever e deixar as ideias claras e, posteriormente, concluir selecionando as que mais se adéquem ao objetivo.

O brainstorming tem como regra não julgar as ideias como boas ou ruins durante o processo, pois o propósito inicial é a quantidade e não a qualidade. Entende-se que qualquer tipo de julgamento prévio poderia inibir a capacidade criativa dos membros por bloqueio mental em defesa a critica, por ideias supostamente ruins. As ideias fornecidas pelos membros em uma sessão de Brainstorming não permitem direito autoral, devem ser fornecidas com a intenção de serem modificadas e desenvolvidas pelo grupo. A referida técnica visa liberar a criatividade e compartilhar ideias, aparentemente incomuns, com o grupo, sem se preocupar se a ideia será boa ou ruim, aproveitada ou não. Valoriza-se nesta circunstância, a espontaneidade (KING; SCHLICKSUPP, 1999).

A sessão de Brainstorming deve ser conduzida por um facilitador, o qual pode fazer comentários ou perguntas que facultem o pensamento criativo em momentos de silêncio, que são denominados ponto morto, ou seja, quando se esgota o estoque de ideias do grupo. A sessão pode ter várias fases até que se aprofunde o pensamento e desenvolvam ideias mais específicas. 


\subsubsection{Desafiando pressupostos}

Desafiando pressupostos é uma técnica que parte da premissa de que ser criativo é romper com pressupostos, consolidados e aceitos sem justificativa racional. Tem o objetivo de auxiliar a solução de problemas com a geração de ideias. Esta técnica não requer uma grande equipe, podendo ser utilizada individualmente e pelo tempo que for necessário (CLEGG; BIRCH, 2000).

A aplicação da técnica consiste em expor o problema ou a necessidade, identificando a principal hipótese como solução, a priori. Clegg e Birch (2000) relatam que nem sempre é possível identificar os pressupostos claramente, mas desafiá-los quando identificados facilita a revelação do real problema. Os autores sugerem trabalhar com um pressuposto por vez, para tornar mais claro e específico o que antes era confuso e só mudar de pressuposto quando esgotadas as alternativas de análise do anterior.

Vianna et al. (2012) complementam que desafiar pressupostos estabelecidos quebra padrões de pensamento, faz com que o colaborador busque soluções inovadoras. O pensamento divergente contribui com a diversidade de ideias, e é valorizado por sua capacidade de contribuir com a concepção de ideias originais (DEGRAFF; LAWRENCE, 2002, MUMFORD; REITER-PALMON; REDMOND in RUNCO, 1994).

\subsubsection{Oposto}

Oposto é uma técnica de criatividade que visa identificar os aspectos inversos ao que se pretende fazer (VOGEL, 2014). Como exemplo, se deseja melhorar um processo na empresa, identifique quais aspectos iriam agravar o referido processo. Conforme explicam Clegg e Birch (2000), é possível que estes aspectos negativos estejam sendo praticados na organização. Cory (2003) e Vogel (2014) afirmam que identificar as nuances do pensamento oposto oferece uma possibilidade ímpar de explorar a fronteira do pensamento, pois quando se chega ao ponto de exaustão de ideias para solucionar um problema, tentar o oposto pode ser positivo, por mudar o ponto de vista sobre o mesmo.

Vale destacar que esta técnica não requer uma grande equipe para a sua execução e nem conhecimento prévio da técnica. Para iniciar, deve-se realizar uma sessão de Brainstorming para identificar os aspectos negativos que poderiam agravar o problema 
(CLEGG; BIRCH, 2000). Após a identificação destes aspectos, deve-se analisá-los e estudar como modificar ou impedir que estas ações ocorram.

Para Clegg (2008) e Manktelow (2010), na sua operacionalização sugere-se dividir o grupo em duas equipes. Uma das equipes deve relatar os aspectos positivos em relação a uma ideia e os integrantes da segunda equipe devem contrapor a ideia, destacando os aspectos negativos. Ao explorar os aspectos positivos e negativos a partir das contribuições dos participantes, dos dois grupos, tende-se obter uma quantidade significativa de ideias que podem oferecer elementos relevantes para a concepção da solução do problema.

\section{ANÁLISE TEÓRICA DE TÉCNICAS DE CRIATIVIDADE}

As técnicas de criatividade, apresentadas anteriormente, abarcam a ideia apresentada por Catmull e Wallace (2014) e Gurteen (1998), de que todos podem ser criativos. De modo geral, a premissa das técnicas de criatividade pressupõe envolver e motivar as pessoas para que possam contribuir para o desenvolvimento de ideias a partir de seu conhecimento e experiência pessoal, vindo, desta forma, ao encontro das afirmações de Mainemelis e Ronson (2006), os quais associam o comportamento organizacional com um jogo que incita o engajamento dos colaboradores e estimula a criatividade por meio das dimensões cognitivas e afetivas que o envolvem.

Ao abordar o ambiente social e a interação com os colaboradores criativos, Csikszentmihalyi (2009), King e Schlicksupp (1999), Puccio e Cabra (in KAUFMAN; STERNBERG, 2010) convergem, apontando a relevância desta interação para a geração de ideias que podem agregar para os resultados da organização, notadamente na concepção de soluções de problemas, ou geração de ideias para novos produtos e serviços.

As técnicas de criatividade se estabelecem como base para potencializar a efervescência da criatividade de forma conduzida, o que é corroborado pela hipótese de Howkins (2013), o qual relata que a criatividade, para ser efetiva, deve ser estimulada e orientada para os resultados desejados.

King e Schlicksupp (1999) e Clegg e Birch (2000) mencionam que há diversas técnicas de criatividade disponíveis na literatura, no entanto, para selecionar as mais adequadas, deve-se saber o que se pretende com a técnica, como exemplo: definir o problema ou gerar uma solução a um problema já identificado? Posteriormente, devem-se saber quais recursos estão disponíveis para aplicação da técnica, bem como, o tamanho do grupo que irá 
participar do processo. Cada técnica exige recursos diferentes, por isso, faz-se necessário ter o conhecimento prévio das variáveis envolvidas.

\begin{tabular}{|c|c|c|c|}
\hline TÉCNICA & OBJETIVO & TAMANHO DE EQUIPE & AUTORES CITADOS \\
\hline $\begin{array}{l}\text { Redefinição } \\
\text { Heurística }\end{array}$ & $\begin{array}{l}\text { Definição do } \\
\text { problema }\end{array}$ & Pequeno ( 1 a 4 pessoas) & $\begin{array}{l}\text { ReVelle (2004), Lubart (2007), } \\
\text { King e Schlicksupp (1999), } \\
\text { Silverstein, Samuel e De Carlo } \\
\text { (2012). }\end{array}$ \\
\hline Bússola & $\begin{array}{l}\text { Definição do } \\
\text { problema }\end{array}$ & Pequeno ( 1 a 4 pessoas) & $\begin{array}{l}\text { Clegg e Birch (2000), Davidson } \\
\text { e Sternberg (2003). }\end{array}$ \\
\hline Brainstorming & $\begin{array}{l}\text { Solução de } \\
\text { problemas }\end{array}$ & Amplo (5 a 10 pessoas) & $\begin{array}{l}\text { Osborn (1954), King e } \\
\text { Schlicksupp (1999), Kelley e } \\
\text { Littman (2001). }\end{array}$ \\
\hline $\begin{array}{l}\text { Desafiando } \\
\text { Pressupostos }\end{array}$ & $\begin{array}{l}\text { Solução de } \\
\text { problemas }\end{array}$ & Pequeno ( 1 a 4 pessoas) & $\begin{array}{l}\text { Clegg e Birch (2000), Vianna et } \\
\text { al. (2012), DeGraff e Lawrence } \\
\text { (2002), Mumford, Reiter- } \\
\text { Palmon e Redmon in Runco } \\
\text { (1994). }\end{array}$ \\
\hline Oposto & $\begin{array}{l}\text { Melhoria de } \\
\text { processos }\end{array}$ & Pequeno ( 1 a 4 pessoas) & $\begin{array}{l}\text { Vogel (2014), Clegg e Birch } \\
\text { (2000), Cory (2003), Clegg } \\
\text { (2008), Manktelow (2010). }\end{array}$ \\
\hline
\end{tabular}

Quadro 1 - Técnicas de Criatividade

Fonte: elaborado pelos autores (2016).

No Quadro 1, sintetizam-se as técnicas de criatividade evidenciadas nesta revisão da literatura. Pode-se identificar que a Redefinição Heurística e a Bússola são técnicas que contribuem para a identificação do problema, propõem-se a manipular os elementos estruturantes do problema para definir claramente o que deve ser resolvido. Já o Brainstorming, o Desafiando Pressupostos e Oposto, são técnicas que visam gerar ideias para solucionar os problemas já definidos anteriormente.

Em geral, estas técnicas são formadas por premissas que visam guiar o pensamento para a criatividade, seguindo alguma lógica cognitiva, com destaque para o pensamento divergente, conforme citado por Gurteen (1998), Lubart (2007), King e Schlicksupp (1999), DeGraff e Lawrence (2002), Mumford, Reiter-Palmon e Redmond In. Runco (1994). As técnicas observadas são de fácil aplicação e, quando aplicadas corretamente, podem contribuir significativamente para alcançar o objetivo da organização. Proporcionam resultados positivos para quem participa da técnica, pois conforme sugerido por Csikszentmihalyi ANIMUS $\begin{aligned} & \text { Revista Interamericana de Comunicação Midiática } \\ & \text { E-ISsn 2175-4977 | v.15 n.30| 2016 | www.ufsm.br/animus }\end{aligned}$ 
(2009), a criatividade, além de promover a inovação, contribui para a valorização das pessoas envolvidas no processo, que se sentem parte da organização contribuindo com seu conhecimento e gerando soluções aos problemas.

As técnicas, que tem como objetivo identificar o problema, seguem a lógica de explorar uma afirmação inicial através do questionamento, para estudar novas facetas que o problema possa evidenciar (KING; SCHLICKSUPP, 1999, CLEGG; BIRCH, 2000). As técnicas que visam gerar ideias para solucionar problemas, em geral, exploram o potencial criativo, buscando gerar a maior quantidade de informações que cada colaborador puder fornecer ao grupo, corroborado por King e Schlicksupp (1999), Clegg e Birch (2000), Cory (2003) e Vogel (2014).

Sob a perspectiva de um jogo, conforme relatam Mainemelis e Ronson (2006) e Gurteen (1998), as técnicas são corroboradas pelo exposto, pois ao serem estruturadas em etapas que visam desenvolver a criatividade, têm o funcionamento de um jogo com base em premissas de engajamento, estimulo de criatividade e dinamismo.

Nota-se que as técnicas expostas focam no resultado do processo criativo, porém não se referem diretamente ao exposto por Amabile (1998), que versa sobre os componentes que favorecem a criatividade: especialidade, motivação e habilidade de pensamento criativo. Focam no processo e não no fator humano que é essencial ao desempenho das técnicas de criatividade. Também se observa que de modo geral as técnicas de criatividade não são exclusivas de um ambiente ou setor específico, podendo ser aplicadas em diferentes setores de uma organização, corroborando o argumento de Gurteen (1998), que enfatiza a relevância da criatividade em todos os setores de um ambiente organizacional.

Por fim, identifica-se que as técnicas apresentadas não fazem menção à questão do ambiente em que serão aplicadas as técnicas, visto que Alencar (1996) respaldado por Amabile (1998) destaca a importância de um alinhamento entre a proposta da técnica e as normas da organização, para estimular a criatividade e não limitá-la.

\section{CONSIDERAÇÕES FINAIS}

A criatividade se manifesta por diversas formas e em diversos campos do conhecimento. Não é algo novo, nem somente exclusividade do campo das artes, da comunicação ou do design. O comportamento criativo é algo inerente ao ser humano, observável desde as tarefas mais simples, como improvisar ou mudar algo da vida cotidiana, 
até tarefas mais complexas como conceber novas teorias no campo das ciências. A restrição que o próprio ser humano cria, é o que muitas vezes limita a possibilidade de melhor aproveitamento das informações para o desenvolvimento da capacidade criativa. Neste sentido, as técnicas de criatividade vêm a contribuir para eliminar tais barreiras e favorecer o fervor dos atos criativos. As técnicas são diversas e pensadas sob diferentes pontos de vista, em geral, todas são apropriadas para aplicar em organizações, condicionadas apenas às características singulares da equipe que fará uso das mesmas e da finalidade de uso.

O uso das técnicas de criatividade nas organizações, pressupõe a intesificação de variáveis comunicacionais entre equipes interdisciplinares, valorizando o saber de cada indivíduo que a integra, ainda que estes aparatos não colaborem de fato na produção do episódio criativo. As técnicas sugerem um caminho para que os usuários destas, encontrem um meio de desenvolver sua capacidade criativa e gerar frutos deste processo.

O objetivo desta pesquisa foi o de apresentar algumas técnicas de criatividade, com base em revisão bibliográfica e é possível afirmar que, desta forma, o mesmo foi atingido. Cabe ressaltar que além das técnicas apresentadas existem diversas outras técnicas de criatividade disponíveis na literatura, no entanto o intuito da pesquisa foi o de selecionar as mais relevantes, que tivessem o foco em definição de problema ou solução de problemas. Enfatizou-se a identificação de suas características principais de aplicação no intento de abordar as diversas formas de desenvolver o pensamento criativo em uma organização.

Em geral, entende-se que para se atingir bons resultados, tratando-se de criatividade, a sinergia entre os integrantes da equipe é efetivamente positiva, isto se torna perceptível na comparação entre setores criativos e tradicionais, como no caso do setor de comunicação, que possuí dinâmicas laborais de mais desenvolvimento e prestígio que outros, facilitando esta sinergia no momento de concepção de ideias. Pensar isoladamente em um problema, utilizando uma técnica de criatividade pode trazer bons resultados, mas pensar coletivamente é de fato mais eficaz, pois cada indivíduo pensará de forma singular e complementará a visão do todo.

Promover a inovação por meio do coletivo confirma a ideia inicial da centralidade do ser humano como elemento constitutivo das organizações, assumindo o espaço que as máquinas ocupavam na era industrial, que foram tão importantes quanto, para a evolução da humanidade.

Cabe ressalvar, entretanto, que se as técnicas de criatividade por si só não geram resultados, o fator humano é essencial para a sua operacionalização. Sendo ainda assim "o 
humano" não é uma constante em uma fórmula, mas uma variável não-matemática, uma variável cultural fundamental. As técnicas elencadas não abordam fatores motivacionais ou mesmo habilidades de pensamento criativo e especialidade do indivíduo, talvez por este motivo é que se declara que a criatividade é prejudicada nas organizações, pois as técnicas são sugeridas para sua aplicação sem evidenciar a necessidade de considerar as singularidades dos colaboradores que irão realizar os processos de criatividade.

Neste sentido é destacada a importância dos indivíduos que realizam os processos de criatividade. Ao analisar estas técnicas propostas, seriam estes métodos, assépticos? E se o foco estiver nas pessoas e não no processo? É a incrível habilidade social e racional do ser humano que torna o processo criativo possível e não somente um conjunto de técnicas aplicadas às cegas.

\section{REFERÊNCIAS}

ADRIAANS, P.; ZANTINGE, D. Data mining. Harlow: Addison-Wesley, 1996.

ALENCAR, E. S. de. A Gerência da Criatividade. São Paulo: Makron Books, 1996.

AMABILE, T. M. How to kill creativity. Harvard Business Review, v. 76, n. 5, p. 76-87, Oct. 1998.

ATEWELL, P.; MONAGHAN, D. B.; Data mining for the social sciences- an introduction. Oakland: University of California Press, 2015.

CATMULL, E.; WALLACE, A. Criatividade S.A.: Superando as forças invisíveis que ficam no caminho da verdadeira inspiração. Tradução de Nivaldo Montingelli Jr. $-1^{\mathrm{a}}$ ed. Rio de Janeiro: Rocco, 2014.

CLEGG, B. Studying Creatively: a creativity toolkit to get your studies out of a rut. Oxon: Routledge, 2008.

CLEGG, B.; BIRCH, P. Criatividade: modelos e técnicas para geração de ideias e inovação em mercados altamente competitivos. São Paulo: Makron Books, 2000.

CORY, T. Brainstorming: Techniques for new ideas. Lincoln: iUniverse Inc., 2003.

CSIKSZENTMIHALYI, M. Creativity: Flow and the Psychology of Discovery and invention. Harper Collins e-books: New York, 2009.

DAVIDSON, J. E.; STERNBERG, R. J. The Psychology of problem solving. Cambridge: Cambridge University Press, 2003. 
DEGRAFF, J.; LAWRENCE, K. A. Creativity at Work: Developing the right practices to make innovation happen. University of Michigan Business School Management Series. San Francisco, CA: John Wiley \& Sons Inc., 2002.

FLORIDA, R. A ascensão da classe criativa. Porto Alegre: L\&PM, 2011.

GREIMAS, A. J. A propósito do jogo. Verso \& Reverso, n. 27. Trad. de Elizabeth Bastos Duarte. São Leopoldo: Unisinos, 1998

GURTEEN, D. Knowledge, Creativity and Innovation. Journal of Knowledge

Management, v. 2, n. 1 p. 5-13, Sep. 1998.

HOWKINS, J. Economia Criativa: Como ganhar dinheiro com ideias criativas. São Paulo: M. Books, 2013.

KAUFMAN, J. C; BAER, J. Beyond new and appropriate: Who decides what is creative? Creative Research Journal, 2012. Disponível em:

<https://s3.amazonaws.com/jck_articles/KaufmanBaer2012.pdf> acesso em 21 jul. 2015.

KELLEY, T.; LITTMAN, J. The art of innovation: Lessons in Creativity from IDEO, America's Leading Design Firm. New York: Doubleday, 2001.

KING, B.; SCHLICKSUPP, H. Criatividade: uma vantagem competitiva. Rio de Janeiro: Qualitymark, 1999.

LUBART, T. Psicologia da criatividade. São Paulo: Artmed, 2007.

MAINEMELIS, C.; RONSON, S. Ideas are born in fields of play: Towards a Theory of Play and Creativity in Organizational Settings. Research in Organizational Behavior, v. 27, p. 81-131, 2006.

MANKTELOW, J. The Mind tools [e-book]: Part I - Tools and Skills for Working with others. 7 ed. Mind Tools Limited, 2010. Disponível em:

https://www.mindtools.com/rs/AMindTools, acesso em 02 out. 2015.

MORAES; M. M. de; LIMA, S. M. V. Estratégias para criar no trabalho. In. ALENCAR, E. M. L. S. de; BRUNO-FARIA, M. de F; FLEITH, D. de S. (cols.). Medidas de Criatividade: teoria e prática. Porto Alegre: Artmed, 2010.

MUMFORD, M. D.; REITER-PALMON, R.; REDMOND, M. R. Problem construction and cognition: Applying problem representations in ill-defined domains. In. RUNCO, M. A.

Problem finding, problem solving and creativity. New Jersey: Ablex Publishing Corporation, 1994.

NEWBIGIN, J. A economia criativa: um guia introdutório. Série economia criativa e cultural 1. Londres: British Council, 2010. Disponível em:

http://creativeconomy.britishcouncil.org/media/uploads/files/Intro_guide_-_Portuguese.pdf, acesso em 28 set. 2015. 
OSBORN, A. Applied imagination: Principles and procedures of creative problem solving. New York: Charles Scribner's Sons, 1954.

PREDEBON, J. Criatividade: abrindo o lado inovador da mente: um caminho para o exercício prático dessa potencialidade, esquecida ou reprimida quando deixamos de ser crianças. $6^{\mathrm{a}}$ ed. São Paulo: Atlas, 2005.

PRODANOV, C. C.; FREITAS, E. C. de. Metodologia do Trabalho Científico [recurso eletrônico]: Métodos e Técnicas da Pesquisa e do Trabalho Acadêmico. $2^{a}$ edição. Novo Hamburgo: Feevale, 2013.

PUCCIO, G. J.; CABRA, J. F. Organizational Creativity: A systems approach. In. KAUFMAN, James C.; STERNBERG, Robert J. The Cambridge Handbook of Creativity. New York: Cambridge University Press, 2010.

REVELLE, J. B. Quality Essentials: a reference guide from A to Z. Milwaukee, Wisconsin: ASQ Quality Press, 2004.

SILVERSTEIN, D.; SAMUEL, P.; DECARLO, N. The Innovator's toolkit - 50+ techniques for predictable and sustainable organic growth. Second Edition. New Jersey: John Wiley \& Sons Inc., 2012.

UNESCO, 2013. Creative Economy Report 2013: Widening local development pathways. Special Ed. Disponível em: http://www.unesco.org/culture/pdf/creative-economy-report2013.pdf, acesso em 28 set. 2015.

VIANNA, M et al. Design Thinking: Business innovation. Rio de Janeiro: MJV Press, 2012.

VOGEL, T. Breakthrough Thinking: a guide to creative thinking and idea generation. Ohio: How Books, 2014. 
Cristiano Max Pereira Pinheiro

Doutor em Comunicação Social pela PUCRS. Professor do

Mestrado em Indústria Criativa na

Universidade Feevale.

Dusan Schreiber

Doutor em Administração e

Professor na Universidade

Feevale.

Bruna Haubert

Mestranda em Indústria Criativa na Universidade Feevale.

Esta obra está licenciada sob uma Licença Creative Commons. 